\title{
Evaluation of octyl p-methoxycinnamate included in liposomes and cyclodextrins in anti-solar preparations: preparations, characterizations and in vitro penetration studies
}

\author{
This article was published in the following Dove Press journal: \\ International Journal of Nanomedicine \\ 19 June 2012 \\ Number of times this article has been viewed
}

Mariana Sato de Souza de Bustamante Monteiro' Rafael Antonio Ozzetti ${ }^{2}$ André Luiz Vergnanini ${ }^{2}$ Lycia de Brito-Gitirana ${ }^{3}$ Nadia Maria Volpato ${ }^{4}$ Zaida Maria Faria de Freitas' Eduardo Ricci-Júnior Elisabete Pereira dos Santos'

'Medicines Department, Federal University of Rio de Janeiro, Rio de Janeiro, ${ }^{2}$ University of Campinas, São Paulo, ${ }^{3}$ Laboratory of Animal and Comparative Histology, Institute of Biomedical Science, Federal University of Rio de Janeiro, Rio de Janeiro, ${ }^{4}$ Department of Production and Medicine Control, Federal University of Rio Grande do Sul, Rio Grande do Sul, Brazil
Correspondence: Eduardo Ricci-Júnior Faculty of Pharmacy, Federal University of Rio de Janeiro, Av Carlos Chagas Filho, 373 CCS, K2-50, 21941-902, Ilha do Fundão, Rio de Janeiro, Brazil

Tel +55 2l 25626625

Fax +55 2I 2260738

Email ricci@pharma.ufrj.br
Purpose: Awareness of the harmful effects of ultraviolet radiation has led to the increasing use of sunscreens, thus, the development of safe and effective antisolar preparations is important. The inclusion of sunscreen molecules in different release systems, like liposomes (lipo) and cyclodextrins (CD) is therefore required.

Methods: The in vivo sun protection factor (SPF), water resistance, and in vitro transdermal penetration test of octyl p-methoxycinnamate $(\mathrm{OMC})$ in different dispersions, such as OMC encapsulated in liposomes (lipo/OMC), OMC encapsulated in $\beta$-cyclodextrins ( $\beta$-CD/OMC), $\mathrm{OMC}$ encapsulated in both release systems (lipo/OMC and $\beta-\mathrm{CD} / \mathrm{OMC}$ ), and an $\mathrm{OMC}$-free formulation were determined.

Results: Although the formulation containing only the lipo/OMC system revealed high value of in vivo SPF $(11.0 \pm 1.3)$ and water resistance $(\mathrm{SPF}=10.3 \pm 2.2)$, the formulation containing both release systems (lipo/OMC $+\beta$-cyclodextrin/OMC) showed the best result in the in vivo SPF test $(11.6 \pm 1.6)$. In the penetration test, the formulation containing the lipo/OMC system had better performance, since a high amount of OMC in the epidermis $(18.04 \pm 1.17 \mu \mathrm{g})$ and a low amount of $\mathrm{OMC}$ in the dermis $(9.4 \pm 2.36 \mu \mathrm{g})$ were observed. These results suggest that liposomes interact with the cells of the stratum corneum, promoting retention of OMC in this layer.

Conclusion: According to our study, the lipo/OMC system is the most advantageous release system, due to its ability to both increase the amount of OMC in the epidermis and decrease the risk of percutaneous absorption.

Keywords: octyl p-methoxycinnamate, sunscreen, liposomes, $\beta$-cyclodextrin, penetration

\section{Introduction}

The harmful effects of ultraviolet (UV) radiation from sunlight ${ }^{1-3}$ have led to the widespread use of topical sunscreen preparations. ${ }^{4,5}$ The most common active ingredients in these preparations are organic sunscreen agents, which absorb UV radiation. ${ }^{6,7}$ A sunscreen can be classified according to its optical and physical characteristics. Optically, an ideal sunscreen should absorb light over a broad spectrum and, physically, cover, protect, and adhere well to the skin, as well as resist removal by water and sweat. ${ }^{8}$

Further, for a sunscreen to be effective, UV absorbers must remain in the outermost layer of the skin. Additionally, an ideal sunscreen should exhibit high skin accumulation of UV absorbers, with minimal permeation to systemic circulation. Once UV absorbers 
penetrate the systemic circulation, photo-protection is lost and the skin becomes susceptible to sun damage. ${ }^{9}$

Octyl p-methoxycinnamate (OMC), an organic UV-B filter originally developed in the $1950 \mathrm{~s}$, has been one of the most widely used sunscreens for decades, and its use in pharmaceutical formulations is allowed by the US Food and Drug Administration, the European Cosmetics, Toiletry and Perfumery Association (COLIPA), the Agência Nacional de Vigilância Sanitária, Brazil, and the Australian Register of Therapeutic Goods. Recent studies have shown that OMC can be detected in deep layers of the skin, urine, and milk after application on the skin. ${ }^{7,10}$ Several approaches have been studied to ensure adequate efficacy for this sunscreen agent, for example, nanocapsules, ${ }^{10}$ microspheres, ${ }^{11}$ cyclodextrins, ${ }^{12,13}$ liposomes ${ }^{13,14}$ and nanoparticles. ${ }^{14}$ The advantage of encapsulating UV filters into nanostructured delivery systems is that they significantly enhance the accumulation of the sunscreen at the administration site to increase water resistance, sun protection factor (SPF), and the photostability of these agents. ${ }^{13-15}$

Cyclodextrins (CD) are cyclic oligosaccharides composed of $\alpha$-D-glucopyranoside linked by glycosidic bonds $(\alpha-1,4)$. They exist in three natural forms, $\alpha, \beta$, and $\gamma$. They can entrap lipophilic drugs into the hydrophobic cavity of their ringed structures. CD are used to increase the aqueous solubility of hitherto poorly soluble drugs, protect against oxidation, and improve photostability. ${ }^{12,13}$

Liposomes are vesicles consisting of one or more concentric phospholipidic bilayers organized around an aqueous inner compartment, and can be produced from nontoxic phospholipids and cholesterol. These vesicles enable the incorporation of both water-soluble and lipidsoluble substances. ${ }^{15-17}$ Liposomes with a high content of soy phosphatidylcholine were used in this study, since they are able to both transport sunscreen agents into the horny layer and form a depot, increasing the amount of $\mathrm{OMC}$ in the skin.

This work aimed to: develop a novel formulation containing OMC loaded in liposomes and $\beta-C D$ with a targeted synergic effect; compare the in vivo SPF, water resistance and in vitro transdermal penetration test of OMC, a usually lipidsoluble sunscreen, in different formulations, such as OMC encapsulated in liposomes (lipo/OMC), OMC encapsulated in $\beta$-cyclodextrins ( $\beta$-CD/OMC), OMC encapsulated in both release systems (lipo/OMC and $\beta-\mathrm{CD} / \mathrm{OMC}$ ), and an OMC free formulation; and prove the separation of the epidermis of the skin by light microscopy.

\section{Methods and materials Materials}

The following materials were used in the formulations: UV-B filter octyl p-methoxycinnamate (OMC) purchased from Merck (Merck KGaA, Darmstadt, Germany), $\beta$-cyclodextrin $(\beta-\mathrm{CD})$ from Wacker-Chemie (Wacker-Chemie $\mathrm{GmbH}$, Munich, Germany), cholesterol and Tris[hydroxymethyl] aminomethane (TRIS) buffer from Sigma-Aldrich (St Louis, MO), Phenova ${ }^{\circledR}$ (phenoxyethanol and parabens) from Croda International, PLC (East Yorkshire, England), Lipoid S $100^{\circledR}$ (phospholipid) from Idealfarma (Anápolis, Goiás, Brazil), Eumulgin ${ }^{\circledR}$ VL 75 (polyglyceryl-2 Dipolyhydroxystearate, lauryl glucoside, glycerin) from Cognis (Monheim, Germany), Structure ${ }^{\circledR}$ XL (hydroxypropyl starch phosphate) from Akzonobel Corporation (Amsterdam, The Netherlands), butylated hydroxytoluene (BHT) from Via Farma Importandora Ltda (São Paulo, SP, Brazil). In addition, chloroform PA and ethanol PA were purchased from Vetec (Vetec Ltda, Rio de Janeiro, Brazil).

\section{Formulation containing free OMC (formulation I)}

A cream formulation containing $8 \%$ of free OMC was prepared to establish a comparison among other formulations. The formulation components and their respective concentrations are listed in Table 1.

\section{Formulation containing liposome/OMC (lipo/OMC) (formulation 2)}

The liposomal sunscreen preparation was obtained by hydration of a phospholipids/OMC film. For this, the lipid film was formed when a formulation of $280 \mathrm{mM}$ phospholipon, $80 \mathrm{mM}$ cholesterol, and $72 \mathrm{mM}$ OMC in chloroform was evaporated (Heidolph Rotary Evaporator, Laborota 4000G1, Schwabach, Germany) and deposited in a round-bottom flask. The film was detached with TRIS buffer by vortex (Marconi, Piracicaba, SP, Brazil) shaking for 15 minutes. ${ }^{18}$ The incorporated OMC corresponded to $20 \%$ of the total phospholipids. A sequential extrusion through polycarbonate membranes $(0.4 \mu \mathrm{m})$, under nitrogen pressure, was performed to homogenize liposome size. ${ }^{18}$ The microdispersion system was characterized using a transmission electron microscope (Morgani 268; FEI, Hillsboro, OR) (under 80 kV). Images were captured using a Megaview G2 digital camera from Olympus (Tokyo, Japan). Incorporation efficiency was measured by UV spectrophotometer (Shimadzu UV-1601, Kyoto, 
Table I Composition of formulations I-4

\begin{tabular}{|c|c|c|c|c|c|}
\hline \multicolumn{6}{|l|}{ Ingredient } \\
\hline Trade names & INCI names & $\begin{array}{l}\text { Free OMC } \\
\text { gel cream }\end{array}$ & $\begin{array}{l}\beta-C D / O M C \\
\text { gel cream }\end{array}$ & $\begin{array}{l}\text { Lipo/OMC } \\
\text { gel cream }\end{array}$ & $\begin{array}{l}\beta-C D / O M C+ \\
\text { lipo/OMC } \\
\text { gel cream }\end{array}$ \\
\hline \multicolumn{6}{|l|}{ Phase A } \\
\hline Structure ${ }^{\circledR} \mathrm{XL}$ & $\begin{array}{l}\text { Hydroxypropyl } \\
\text { starch phosphate }\end{array}$ & $5 \% w / w$ & $5 \% w / w$ & $5 \% w / w$ & $5 \% \mathrm{w} / \mathrm{w}$ \\
\hline Distilled water & Water & qbl00.0 & qbl00.0 & qbl00.0 & qbl00.0 \\
\hline \multicolumn{6}{|l|}{ Phase B } \\
\hline Eumulgin $^{\circledR}$ & Polyglyceryl-2 & $3 \% w / w$ & $3 \% w / w$ & $3 \% w / w$ & $3 \% w / w$ \\
\hline VL 75 & $\begin{array}{l}\text { Dipoly-hydroxystearate, } \\
\text { lauryl glucoside }\end{array}$ & & & & \\
\hline Phenova & $\begin{array}{l}\text { Phenoxyethanol } \\
\text { and parabens }\end{array}$ & $0.5 \% \mathrm{w} / \mathrm{w}$ & $0.5 \% \mathrm{w} / \mathrm{w}$ & $0.5 \% \mathrm{w} / \mathrm{w}$ & $0.5 \% \mathrm{w} / \mathrm{w}$ \\
\hline BHT & $\begin{array}{l}\text { Butylated } \\
\text { hydroxytoluene }\end{array}$ & $0.05 \% \mathrm{w} / \mathrm{w}$ & $0.05 \% \mathrm{w} / \mathrm{w}$ & $0.05 \% \mathrm{w} / \mathrm{w}$ & $0.05 \% \mathrm{w} / \mathrm{w}$ \\
\hline OMC & $\begin{array}{l}\text { Octyl } \\
\text { methoxycinnamate }\end{array}$ & $8 \% w / w$ & $4.75 \% \mathrm{w} / \mathrm{w}$ & $4.38 \% \mathrm{w} / \mathrm{w}$ & $4 \% w / w$ \\
\hline Lipo/OMC & & & $\begin{array}{l}3.25 \% \text { of } \\
\text { OMC }=50 \mathrm{~mL} \text { of } \\
\text { lipo/OMC }\end{array}$ & $\begin{array}{l}\text { I.62\% of } \\
\text { OMC }=25 \mathrm{~mL} \text { of } \\
\text { lipo/OMC }\end{array}$ & \\
\hline$\beta-C D / O M C$ & & & & $\begin{array}{l}2 \% \text { of } \\
O M C=6.63 \mathrm{~g} \text { of } \\
\beta-C D / O M C\end{array}$ & $\begin{array}{l}4 \% \text { of } \\
O M C=13.26 \mathrm{~g} \text { of } \\
\beta-C D / O M C\end{array}$ \\
\hline
\end{tabular}

Abbreviations: $\beta-C D, \beta$-cyclodextrins; INCl, International Nomenclature of Cosmetic Ingredients.

Japan). Particle size distribution, polydispersity index, and zeta potential were obtained using a particle size analyzer (Zetasizer ${ }^{\circledR}$ Nano Z; Malvern Instruments, Worcestershire, UK).

The lipo/OMC inclusion complex was manually incorporated in a cream with an OMC concentration of $8 \%$. The formulation components are described in Table 1.

\section{Formulation containing $\beta-C D / O M C$ (formulation 3)}

The Kneading method was employed to include the OMC in the cavity of the $\beta-C D$. This method is suitable for complexation of water-insoluble compounds. ${ }^{18} \beta-\mathrm{CD}$ and $\mathrm{OMC}$ at a ratio of 1.7:1 were mixed together for 5 minutes. After that, $1.0 \mathrm{~mL}$ of ethanol:water (70:30) solution was added to the formulation, and a mass was formed. ${ }^{18-20}$ The product (total mass $20 \mathrm{~g}$ ) was then transferred to a ball mill (11 cm long and $8 \mathrm{~cm}$ diameter), containing $27 \mathrm{~g}$ of porcelain balls (average diameter $1 \mathrm{~cm}$ ). The mixture was kept in the mill for 1 hour. It was then purified with a $50 \%$ methanol:water solution and dried at $55^{\circ} \mathrm{C}$ for 30 minutes. ${ }^{19,20}$ Complex formation was characterized by ${ }^{1} \mathrm{H}$-nuclear magnetic resonance (NMR) spectroscopy (Gemini-200 MHZ; Varian, Palo Alto, CA) and X-ray diffractometry (Rigaku-Miniflex,
Tokyo, Japan); complex yield was determined by UV spectrophotometer (UV-1601; Shimadzu, Kyoto, Japan). ${ }^{20}$

The $\beta$-CD/OMC inclusion complex was manually incorporated in a cream with an OMC concentration of $8 \%$. The formulation components are described in Table 1.

\section{Formulation containing $\beta-\mathrm{CD} / \mathrm{OMC}$ and lipo/OMC (formulation 4)}

Both $\beta-\mathrm{CD} / \mathrm{OMC}$ and lipo/OMC inclusion complexes were incorporated in a cream with an OMC concentration of $8 \%$. The formulation components are listed in Table 1.

\section{In vitro SPF determination}

SPF values were determined according to the method described by Mansur et al, ${ }^{21}$ which was corroborated by Santos et $\mathrm{al}^{22}$ and Freitas et $\mathrm{a}^{23}$ using similar experimental conditions. Sunscreen formulations containing both free $\mathrm{OMC}$ and $\mathrm{OMC}$ included in the delivery systems were prepared.

Absorbance values of each preparation at a final concentration of $2 \mu \mathrm{L} / \mathrm{mL}$ diluted in ethanol (in triplicate) were determined under the emission spectrum of $290-320 \mathrm{~nm}$, with $5 \mathrm{~nm}$ intervals, using a Shimadzu UV-1601 UV-visible spectrophotometer. The SPF determination, equation 1 
(mathematical expression of Mansour et al), ${ }^{21}$ and the correlation between the erythemogenic effect (EE) and the radiation intensity at each wavelength $(\mathrm{EE} \times \mathrm{I})$ were adjusted according to Sayre et al ${ }^{24}$ (Table 2).

$$
\text { Spectrophotometric } \mathrm{SPF}=\mathrm{CF} \sum_{290}^{320} \operatorname{EE}(\lambda) \mid(\lambda) \text { abs }(\lambda)
$$

where $\mathrm{CF}=10$ (correction factor), $\operatorname{EE}(\lambda)=$ erythemogenic effect of radiation of wavelength $\lambda, I(\lambda)=$ intensity of solar light with wavelength $\lambda$, abs $(\lambda)=$ spectrophotometric absorbance value of a solution of the preparation at wavelength $\lambda$.

\section{In vivo SPF determination}

The SPF value (equation 2) is defined as the ratio between the UV energy required to produce a minimum erythemal dose (MED) - or redness - on protected skin and the UV energy required to produce $\mathrm{MED}$ on unprotected skin.

$$
\mathrm{SPF}=\frac{\text { MED of protected skin }}{\text { MED of unprotected skin }}
$$

SPFs were determined in vivo according to the COLIPA method. ${ }^{25-27}$ Ten individuals with skin phototypes (SPT) I, II, and III, aged 18-42 years, were used as volunteers. The back of each volunteer was exposed to UV, using a 601 Multiport UV Solar Simulator (Solar Light Company, Glenside, PA). Volunteers were informed about the protocols, agreed to participate in the study, and gave written consent. All studies were made by Alergisa (Campinas, SP, Brazil) according to Brazilian ethical protocol.

SPFs were obtained using the following in vivo method. On the first day, the volunteers' backs were exposed to a UV simulator; the exposure times varied according to the skin types. After about 20 hours, the MEDs of each volunteer were observed. On the second day, the MEDs without sunscreen were verified and then the tested sunscreen was applied. The sunscreen samples and standard formulation were applied in

Table 2 Weight employed to determine sun protection factor by spectrophotometry

\begin{tabular}{ll}
\hline$\lambda(\mathrm{nm})$ & $\operatorname{EE~}(\lambda) \times I(\lambda)$ \\
\hline 290 & 0.0150 \\
295 & 0.0817 \\
300 & 0.2874 \\
305 & 0.3278 \\
310 & 0.1864 \\
315 & 0.0839 \\
320 & 0.0180 \\
& 1.0000 \\
\hline
\end{tabular}

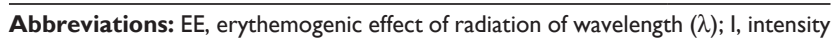
of solar light with wavelength $(\lambda)$. the amount of $2 \mathrm{mg} / \mathrm{cm}^{2}$ to an adjacent area of the same back of each volunteer. After application, the product was left to dry for 15 minutes before irradiation. Each test area was exposed to controlled amounts of simulated sunlight using a solar simulator with continuous emission spectrum of 290-400 nm. An area of $5 \times 6 \mathrm{~cm}$ was irradiated in six points (diameter of $1 \mathrm{~cm}$ ) in a series of geometrically increasing doses. The standard formulation was a lotion with $7 \%$ of octyl dimethyl PABA and 3\% of benzophenone-3. On the third day, the MEDs of the sunscreens were again analyzed and then the SPF for the product was calculated using the arithmetic average of all the individual SPF values obtained from each volunteer. ${ }^{25-26}$

\section{SPF determination after \\ in vivo immersion}

The SPF subsequent in vivo immersion was determined according to COLIPA with ten volunteers aged 18-42 years with SPT I, II, and III, whose backs were exposed to UV ${ }^{25}$ using a 601 Multiport UV Solar Simulator.

The term "water resistant" means that the sunscreen photoprotective effect remains 40 minutes after exposure to water. The water resistance component was determined by evaluating the volunteers after two cycles of 20-minute immersion intervals, with moderate activity in water, each followed by a 20-minute rest/air dry period until the total water exposure time was reached. The test areas were air dried without toweling at the end of the last water-immersion period. ${ }^{25-27}$

Experimental data are presented as mean \pm standard deviation. To compare both the absorbance and in vivo SPF values of the sunscreen preparations, data were analyzed by one-way analysis of variance $(P=0.05)$, using the SigmaStat for Windows software (v 3.11; Cranes Software, Chicago, IL).

\section{In vitro cutaneous penetration test}

\section{Skin preparation}

Skins from the ears of 4-month-old female pigs were obtained at the Federal Rural University of Rio de Janeiro, Brazil. An internationally validated and accepted animal-free test method (SCCNFP/0119/99) is available. Pig ear skin is a very attractive model for in vitro percutaneous absorption studies since it mimics human skin.

Immediately following slaughter, the pig ears were removed before receiving a hot bath. After this, they were taken as quickly as possible under cooling to the laboratory, where they were shaved and washed under running water. Later, the ear skins of the dorsal region were cut with scalpel and scissors to eliminate excess adipose tissue from the 
ventral region. ${ }^{28,29}$ Then rounded pieces of skin approximately $11 \mathrm{~cm}^{2}$ were maintained in airtight conditions within a film of polyvinyl chloride (PVC) and foil and stored at $-20^{\circ} \mathrm{C}$ for no longer than 4 weeks before use (only intact skin discs with an effective permeation area of $1.96 \mathrm{~cm}^{2}$ were kept). Prior to the in vitro cutaneous penetration test, the skin surface (epidermal side) was cleaned with $0.5 \mathrm{~mL}$ aqueous solution of sodium lauryl sulfate $(1 \%$; $1 \mathrm{~g}$ sodium lauryl sulfate $/ 99 \mathrm{~g}$ water) impregnated in cotton. The remaining fat on the dermal side was entirely removed with ether impregnated in cotton. Then the skin was washed five times with distilled water and dried with dry cotton to maintain skin integrity. ${ }^{28,29}$

\section{Histology of pig skin}

To analyze the in vitro distribution of OMC into the skin layers, the epidermis was separated from the dermis. Histological analysis was then performed to evaluate the procedure that allowed the separation of the skin layers by scalpel. The skins were heated at $60^{\circ} \mathrm{C}$ for 30 seconds. After that, from a half segment the epidermis was removed using a scalpel. Figure 1 illustrates the procedure of the epidermis removal used in the present study.

The rounded pieces were cut into small fragments $(5 \times 2 \mathrm{~cm})$, fixed with $10 \%$ buffered formaldehyde and/or Bouin's liquid, and processed according to standard histological techniques for paraffin embedding. Five-micrometer thick slices, obtained using a Leica 2025 microtome (Wetzlar, Germany), were stained with hematoxylin-eosin. ${ }^{30}$

\section{Diffusion cell preparation}

Initially, to establish sink conditions, the solubility of OMC was studied in different receptor media. ${ }^{9,31}$ Four receptor

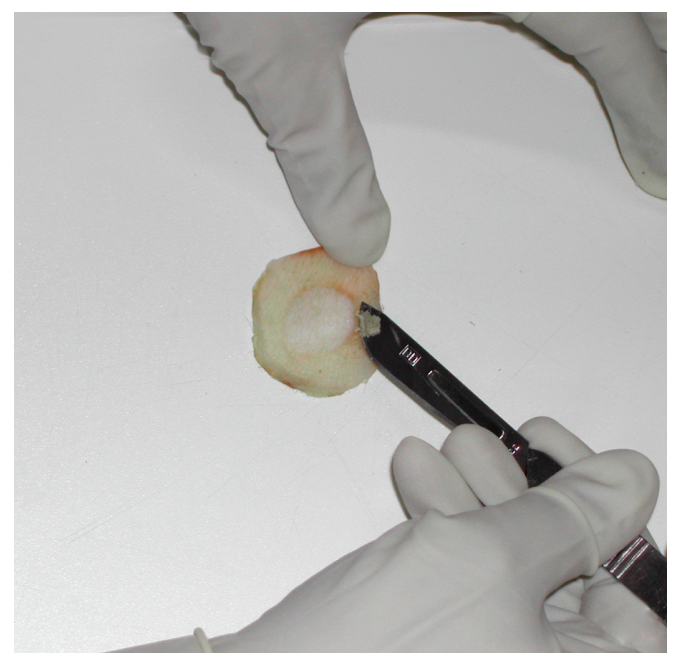

Figure I Removal of the epidermis using a scalpel. solutions were studied: (1) phosphate buffer $\mathrm{pH} 7.4$ and phosphate buffer $\mathrm{pH} 7.4$ containing (2) $2 \%$, (3) $4 \%$, or (4) $5 \%$ polysorbate 80 . OMC in excess was added to $5 \mathrm{~mL}$ of each receptor medium. The samples were shaken for 24 hours at $25^{\circ} \mathrm{C}$ and were then centrifuged $(8000 \mathrm{~g}$ ) for 15 minutes, filtered through a Millipore filter (pore size $0.45 \mu \mathrm{m}$; Millex HV, Millipore, Brazil), and diluted with receptor media. The concentration of the OMC was determined by absorption spectroscopy using a wavelength of $310 \mathrm{~nm}$.

The skin samples were mounted in modified Franz diffusion cells with a surface of $1.96 \mathrm{~cm}^{2}$ and a receptor volume of $7.5 \mathrm{~mL}$, allowing the dermal side of the skin to be exposed to the receptor fluid and the stratum corneum exposed to the air so that the receptor fluid would not adversely affect the superficial skin layers or the physicalchemical properties of OMC.

The receptor fluid ( $\mathrm{pH}$ 7.4) consisted of $120 \mathrm{mM} / \mathrm{L}$ phosphate-buffered saline solutions containing sodium chloride $(\mathrm{NaCl})$, potassium chloride $(\mathrm{KCl}) 2.7 \mathrm{mM} / \mathrm{L}$, and $10 \mathrm{mM} / \mathrm{L}$ phosphate buffer, containing $5 \%$ Tween $^{\circledR} 80$. The solubility of $\mathrm{OMC}$ in the receptor fluid was checked prior to commencement of experiments since OMC under these conditions is readily soluble in the receptor fluid.

Products were applied to the skin at a finite dose of $400 \mu \mathrm{g} / \mathrm{cm}^{2}$ using an automatic pipette so that the formulation film could cover the entire skin surface with a uniform and homogenous spread without determining its thickness. The cell was filled with $7.5 \mathrm{~mL}$ of receptor fluid through a lateral inlet using a burette. Visible air bubbles, between the bottom side of the skin and the receptor fluid, were eliminated through a lateral inlet.

The diffusion cells were placed in a thermostat-controlled water bath with horizontal agitation (speed of 900 strokes per minute), assuring both the homogeneity of the receptor fluid and the mean skin temperature of $32^{\circ} \mathrm{C} \pm 0.1{ }^{\circ} \mathrm{C}$. Four replicates were used for the study. A $1 \mathrm{~mL}$ aliquot was taken for analysis at predetermined intervals (1 hour and 2, $3,4,5$, and 6 hours), then the volume was replaced with the receiver solution. After that, $\mathrm{OMC}$ levels were analyzed by high-performance liquid chromatography (HPLC). ${ }^{18}$

\section{In vitro distribution of OMC into the pig skin layers}

Six hours later, the skin was removed from the cell using tweezers and the formulation excess was removed from the skin surface, which was cleaned twice with moistened cotton and once with dried cotton. After that, the epidermis was separated from the dermis using a scalpel. 
To determine the quantity of $\mathrm{OMC}$, the remaining product on the skin surface was dissolved using methanol and each sample was shaken with a vortex mixer, before being agitated for 1 minute, submitted to ultrasound for 12 minutes, and centrifuged at $6400 \mathrm{rpm}$ for 10 minutes. Subsequently, an aliquot of this last solution was dissolved in methanol to determine the amount of OMC remaining on the skin surface. OMC levels were analyzed by HPLC. ${ }^{18}$

\section{HPLC analysis}

The concentrations of OMC in the formulations, in the skin layers (epidermis and dermis), and in the receptor fluid, were chromatographically determined by an isocratic HPLC system. The HPLC system consisted of a Waters model 510 pump with a Waters model $486 \mathrm{UV}$-Vis detector, a Rheodyne injector (Waters 717) with a $20 \mu \mathrm{L}$ loop and a Waters 486 recorder (Waters Corporation, Milford, MA). Data acquisition and processing were accomplished with a Waters data model 7466, Hamilton 80665 Integrator (Sigma-Aldrich).

OMC was determined using a Hibar ${ }^{\circledR}$ LiChrosorb, a $5 \times 25 \mathrm{~cm}$ reverse-phase column $\left(\mathrm{C}_{18}\right)$ (Merck) operated at room temperature, and eluted with a mobile phase consisting of methanol/water $(87: 13)$ at a flow-rate of $1.0 \mathrm{~mL}$ minute ${ }^{-1}$. The column effluent was continuously monitored at $310 \mathrm{~nm}$ to detect OMC. ${ }^{18}$ Quantification of the compound was performed by measuring the peak areas in relation to those of chromatographed standards under the same conditions. The sensitivity of the HPLC method was $0.1 \mu \mathrm{g} \mathrm{mL}^{-1}$ for OMC.
A standard stock solution of OMC $(20 \mu \mathrm{g} / \mathrm{mL})$ was prepared by dissolving the filter in methanol. The calibration curve was prepared with methanol solutions of OMC at concentrations ranging from 1 to $20 \mu \mathrm{g} / \mathrm{mL}$. The standard curves were linear $(r=0.999)$. In addition, the validation results were established for five concentrations through three injections per concentration. The reproducibility of the method was expressed by the relative standard deviation.

\section{Statistics}

Experimental data are presented as mean \pm standard deviation. The difference in the concentrations of the sunscreen agent in the receptor fluid, epidermis, and dermis for each formulation, was compared by one-way analysis of variance $(P=0.05)$, using the SigmaStat software. A $P$ value of $<0.05$ was considered statistically significant.

\section{Results \\ Lipo/OMC complex characterization}

The liposomes obtained from the dry phospholipid film revealed spherical vesicles, which were morphologically homogeneous (Figure 2). The roughness of the vesicles was due to the treatment of the sample prior to electron microscopy. The sample was diluted, stained with uranyl acetate and dried before microscopy, and this drying caused the liposomes to become rough. Average diameters of liposomes containing OMC and empty liposomes were $957.5 \pm 12.1$ (polydispersity index [PI] 0.45) and $941.2 \mathrm{~nm} \pm 27.3$ (PI 0.23)

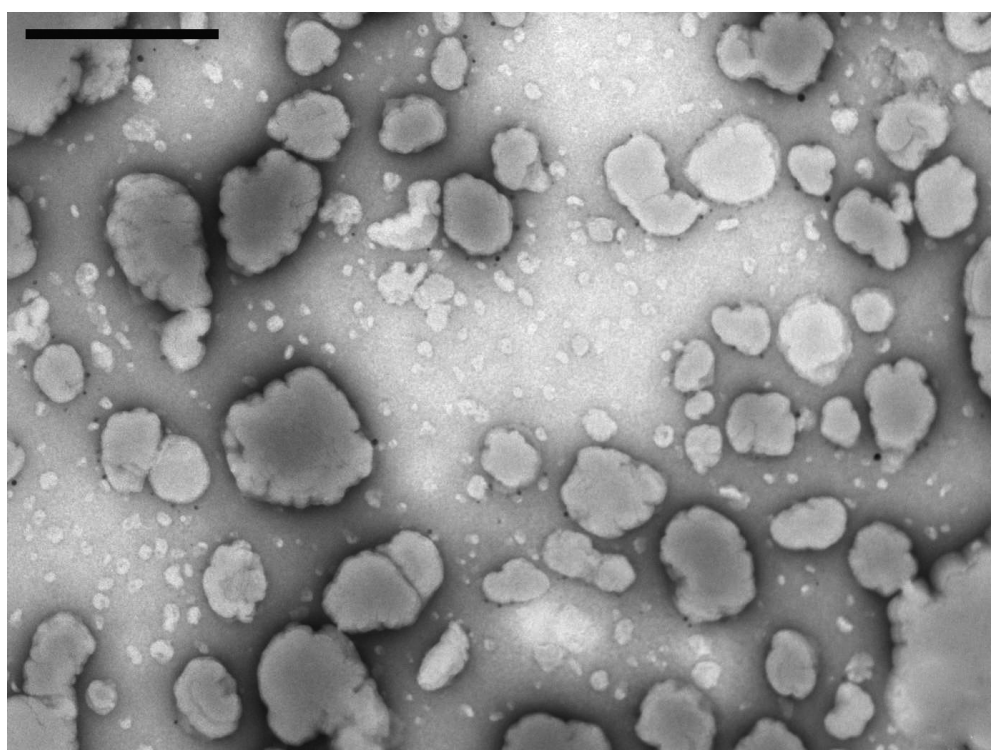

Figure 2 Electron micrograph of liposomes formed after the hydration of the dry phospholipids film containing OMC.

Note: Scale bar $=500 \mathrm{~nm}$.

Abbreviation: OMC, octyl p-methoxycinnamate. 
$(n=3)$, respectively. PI evaluates the quality of the sample.

$\mathrm{PI}<0.1$ indicates that the range of size distribution is narrow and monomodal. PI $<0.5$ indicates a wide range. Our results provide PI $<0.5$, showing that the quality is satisfactory. The lipsomes' incorporation efficiency for containing OMC was $88.88 \%(n=3)$. The zeta potential of liposomes containing $\mathrm{OMC}$ and empty liposomes was $-11.8 \pm 0.2 \mathrm{mV}$ and $-10.2 \pm 0.1(\mathrm{n}=3)$, respectively.

\section{$\beta-C D / O M C$ complex characterization}

Table 3 shows the up-field shifts (negative $\Delta \delta$ values) observed for the OMC aromatic proton signals, using ${ }^{1} \mathrm{H}-\mathrm{NMR}$ spectral studies (Figure 3A and B), suggesting that the aromatic portion of the sunscreen molecule (Figure 3C) is located inside the cyclodextrin cavity (Figure 3D), with the ester group close to the external surface of the macrocycle. ${ }^{12}$

The molecular volume is the main restrictive factor of the inclusion process of sunscreens in the cavity of cyclodextrins. ${ }^{32}$ The molecular volume of $\mathrm{OMC}$, calculated by molecular modeling, was larger $\left(367.53 \AA^{3}\right)$ than the cavity of the $\beta-C D$ (cavity volume $\left.=262 \AA^{3}\right) .{ }^{20}$ The inclusion of OMC in $\alpha-\mathrm{CD}\left(174 \AA^{3}\right)$ produces low reproducibility and yield; however, the use of $\gamma$-CD $\left(472 \AA^{3}\right)$ produces an increase in the yield (20\%). The results show that molecular volume is the major restrictive parameter of the inclusion process of sunscreens in $\mathrm{CD} .{ }^{20}$ Additionally, as illustrated in Figure 4, the peaks of $\mathrm{OMC}$ of the physical sunscreen formulation with cyclodextrin observed through the X-ray diffraction pattern were absent in the diffractogram of the complex. These results provide evidence of the inclusion of OMC in the $\beta$-CD cavity. Moreover, the incorporation efficiency of $\mathrm{OMC}$ in the $\beta$-CD cavity was $89.0 \%(\mathrm{n}=3)$.

\section{In vitro SPF}

The absorbance and SPF values for formulations 1-4 are shown in Figure 5. There was no significant statistical difference between the in vitro SPF values of the developed sunscreen preparations $(P=0.600)$.

Table 3 'H-nuclear magnetic resonance chemical shift changes $(\Delta \delta, \mathrm{ppm})$ for OMC in cyclodextrins

\begin{tabular}{llll}
\hline Protons & OMC & $\beta$-CD/OMC complex & $\begin{array}{l}\Delta \delta^{*} \\
\beta-C D / O M C\end{array}$ \\
\hline $\mathrm{H}_{3} \mathrm{H}_{5}$ & $6.8 \mathrm{ppm}$ & $6.5 \mathrm{ppm}$ & $-0.30 \mathrm{ppm}$ \\
$\mathrm{H}_{2} \mathrm{H}_{6}$ & $7.6 \mathrm{ppm}$ & $7.2 \mathrm{ppm}$ & $-0.40 \mathrm{ppm}$ \\
$\mathrm{H}_{1^{\prime}}$ & $6.4 \mathrm{ppm}$ & $6.0 \mathrm{ppm}$ & $-0.40 \mathrm{ppm}$ \\
$\mathrm{H}_{2^{\prime}}$ & $7.6 \mathrm{ppm}$ & $7.1 \mathrm{ppm}$ & $-0.50 \mathrm{ppm}$ \\
\hline
\end{tabular}

Note: $\Delta \delta^{*}=\delta$ with cyclodextrins - pure $\delta$ OMC.

Abbreviations: OMC, octyl $\mathrm{p}$-methoxycinnamate; $\beta$-CD, $\beta$-cyclodextrins.

\section{In vivo SPF}

Erythema development at the analyzed areas was regarded as acceptable. Further, after UV radiation exposure, an area without erythema between areas of increasing erythema extension was observed. Calculated SPF values for formulations 1-4 are shown in Figure 5. Statistical analysis showed that the in vivo SPF values for sunscreen preparations were significantly different $(P<0.001)$, since formulations with liposomes (lipo/OMC and $\beta-\mathrm{CD} / \mathrm{OMC}+$ lipo/OMC) provided different SPFs. However, no significant statistical difference was observed between the preparation with both complexes $(\beta-\mathrm{CD} / \mathrm{OMC}+$ lipo/OMC) and lipo/OMC complex, or between preparations containing free $\mathrm{OMC}$ and $\beta$-CD/OMC complex $(P>0.05)$.

The formulations containing the lipo/OMC $+\beta-\mathrm{CD} /$ $\mathrm{OMC}$ systems and the lipo/OMC release system exhibited the highest in vivo SPF values (Figure 5).

\section{After immersion in vivo SPF}

The SPF values for formulations 1-4 are shown in Figure 5. After in vivo immersion, the SPF values showed a significant statistical difference among preparations with complexes $(\beta-\mathrm{CD} / \mathrm{OMC}+$ lipo/OMC), free $\mathrm{OMC}$ and $\beta$-CD/OMC complex $(P<0.05)$. There was also a significant difference among formulations with lipo/OMC complex. However, there was no significant statistical variation between the preparation containing both complexes $(\beta-\mathrm{CD} / \mathrm{OMC}+$ lipo/ $\mathrm{OMC}$ ) and lipo/OMC complex and between the preparation with free OMC and $\beta-\mathrm{CD} / \mathrm{OMC}$ complex $(P>0.05)$.

Figure 5 reveals that the liposomes incorporated with OMC increased the in vivo SPF $(P<0.05)$ and water resistance $(P>0.05)$. The inclusion of OMC in $\beta-\mathrm{CD}$ did not promote an increase of the in vivo SPF value $(P>0.05)$ and did not show any increase in water resistance $(P<0.05)$. The formulation with the lipo/OMC complex showed the best result.

\section{In vitro cutaneous penetration test}

Histological analysis confirmed that the method used separates the epidermis from the dermis. Figure 6 shows the skin of a pig ear and the epidermis layers, including the stratum corneum. Additionally, when the scalpel was used, the epidermis was entirely removed and the dermis remained intact. The separation of both skin layers is important for penetration tests, which measure the amount of OMC in each layer, and avoid tissue contamination.

OMC solubility in the receptor media is shown in Table 4. Sink conditions were established to prevent the formation of 
A 
C

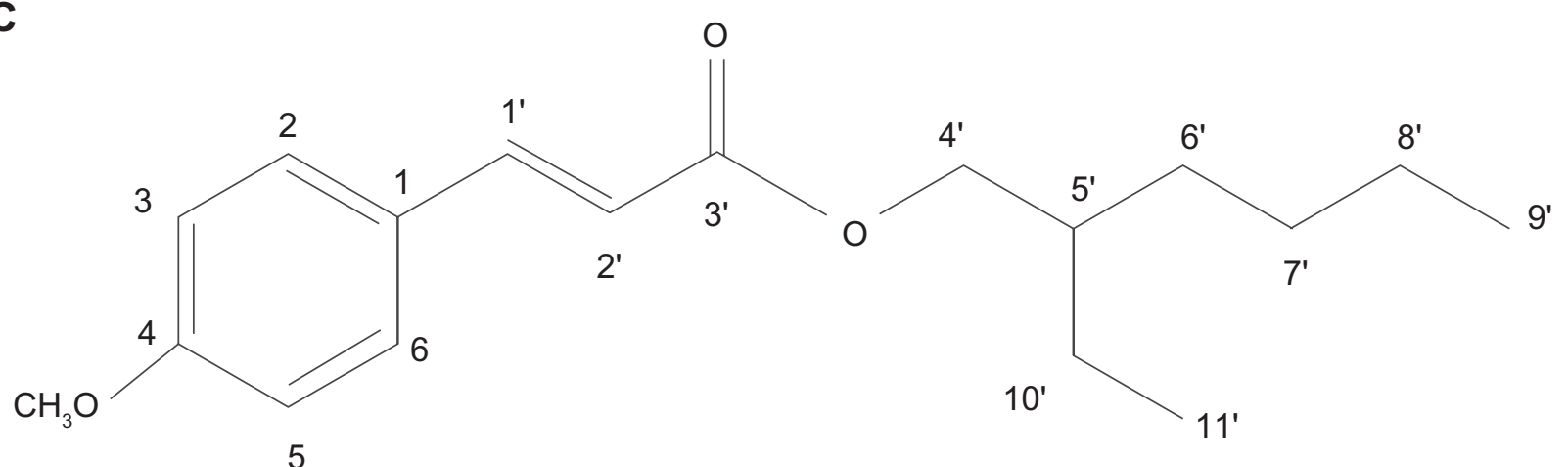

D

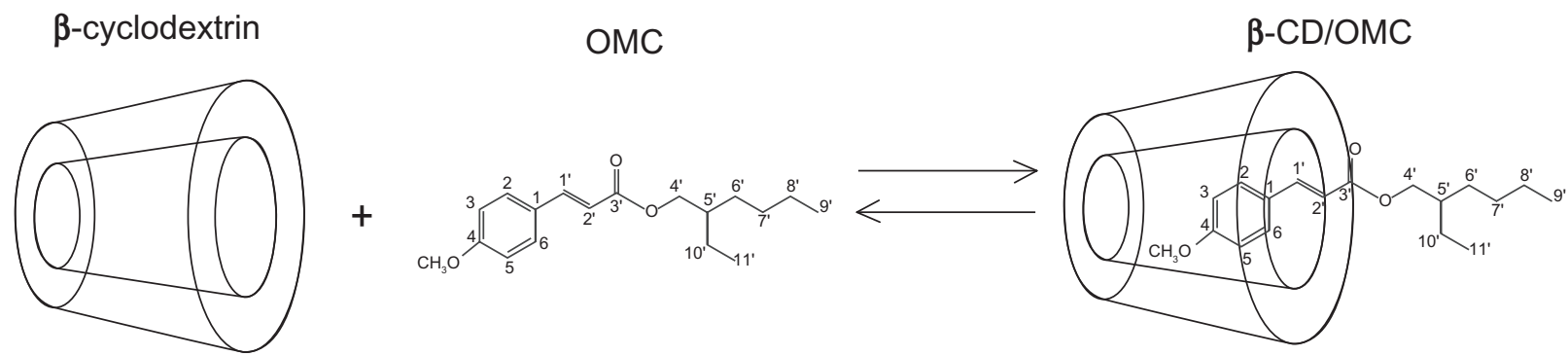

Figure 3 (Continued)

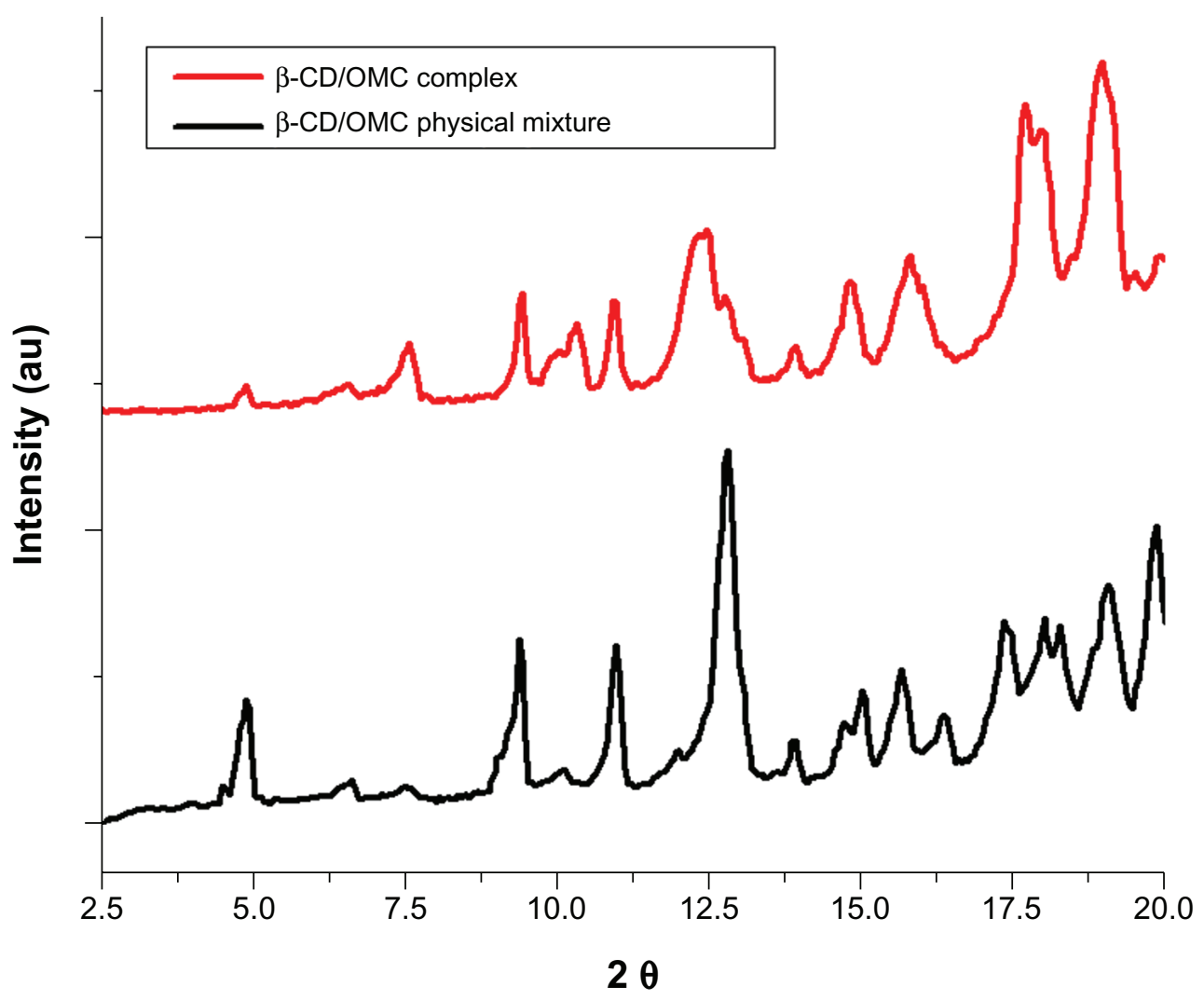

Figure 4 Powder X-ray diffraction patterns of $\beta$-CD/OMC (2:I) physical formulation (black) and $\beta$-CD/OMC (2:I) complex (red). Abbreviations: OMC, octyl p-methoxycinnamate; $\beta$-CD, $\beta$-cyclodextrins. 


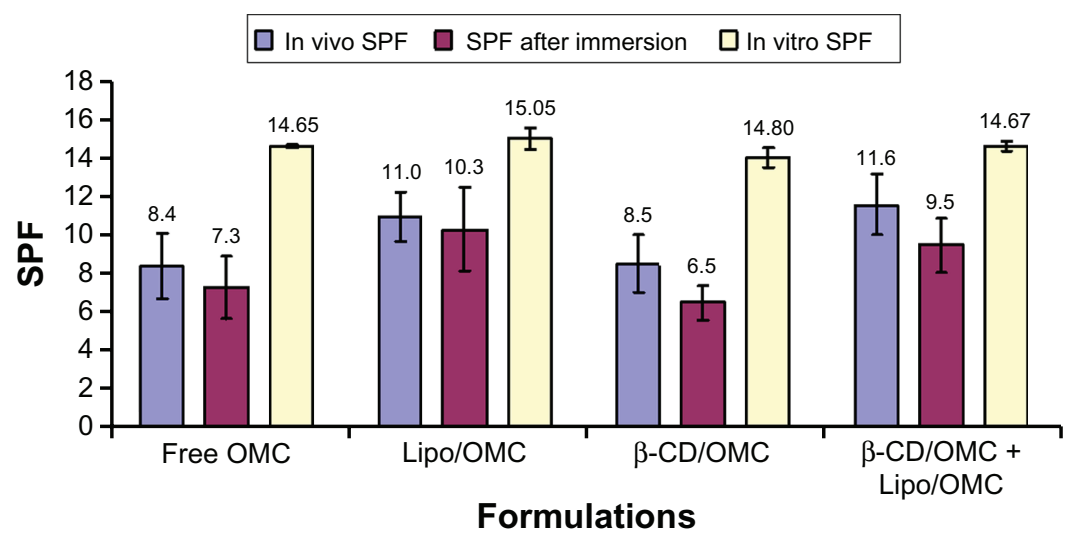

Figure 5 In vivo values after immersion and in vitro SPF of cream with free OMC (A), cream with lipo/OMC complex (B), cream with $\beta$-CD/OMC complex (C), and cream with both complexes (D) (mean \pm standard deviation).

Abbreviations: $\beta$-CD, $\beta$-cyclodextrins; OMC, octyl p-methoxycinnamate; SPF; sun protection factor.

saturated solution of the drug during the in vitro permeation study. Thus, the maximum concentration of the OMC released in the receptor media was five times smaller than the saturation concentration of sunscreen in this medium. ${ }^{33}$

The solubility of the sunscreen in phosphate buffer pH 7.4 was $37.2 \mu \mathrm{g} / \mathrm{mL}$. OMC is lipophilic and has low solubility in aqueous media. The addition of $2 \%, 4 \%$, or $5 \%$ polysorbate 80 as a surfactant increased the solubility of the OMC in the receptor medium (Table 4). Phosphate buffer pH 7.4 containing $5 \%$ polysorbate 80 was chosen as the receptor medium because it provided the highest solubility $(271.1 \mu \mathrm{g} / \mathrm{mL})$. The concentration of sunscreen in the receptor medium should not exceed $54.22 \mu \mathrm{g} / \mathrm{mL}$ (20\% of the saturation concentration of the $\mathrm{OMC}=271.1 \mu \mathrm{g} / \mathrm{mL}$ ) to maintain sink conditions. Thus, the permeation studies were performed in sink conditions, as $50 \mu \mathrm{g} / \mathrm{mL}$ corresponds to the maximum concentration of $\mathrm{OMC}$ able to be released during the permeation study.

The amounts of OMC per $\mu \mathrm{g}$ from both epidermis and dermis for formulations 1-4 are presented in Figure 7. The statistical analysis revealed that the amounts of OMC in the epidermis $(P=0.066)$ and in the dermis $(P=0.251)$ for the four formulations were similar. However, a statistical difference

Table 4 Octyl p-methoxycinnamate solubility in the receptor medium

\begin{tabular}{ll}
\hline Receptor medium & Solubility $(\mu \mathrm{g} / \mathrm{mL})$ \\
\hline Phosphate buffer $\mathrm{pH} 7.4$ & 37.2 \\
Phosphate buffer $\mathrm{pH} 7.4$ containing $2 \%$ & 111.8 \\
(w/w) de polysorbate 80 & \\
$\begin{array}{l}\text { Phosphate buffer } \mathrm{pH} 7.4 \text { containing } 4 \% \\
\text { (w/w) de polysorbate } 80\end{array}$ & 215.1 \\
$\begin{array}{l}\text { Phosphate buffer } \mathrm{pH} 7.4 \text { containing } 5 \% \\
(w / w) \text { de polysorbate } 80\end{array}$ & 271.1 \\
\hline
\end{tabular}

$(P=0.037)$ in the amount of OMC between the epidermis and dermis in the lipo/OMC formulation was detected.

The amounts of $\mathrm{OMC}$ in epidermis and dermis for the free OMC formulation were $11.95 \pm 4.41 \mu \mathrm{g}$ and $12.38 \pm 2.98 \mu \mathrm{g}$, respectively. The amounts of OMC for the $\beta-\mathrm{CD} / \mathrm{OMC}$ formulation were $11.13 \pm 3.36 \mu \mathrm{g}$ and $14.18 \pm 3.59 \mu \mathrm{g}$, respectively, and the amounts of OMC for the lipo/OMC formulation were $18.04 \pm 1.17 \mu \mathrm{g}$ and $9.4 \pm 2.36 \mu \mathrm{g}$, respectively. Furthermore, the concentrations of OMC in the epidermis and dermis showed some statistical difference $(P=0.037)$.

Nevertheless, the amounts of $\mathrm{OMC}$ in the pig skin for the $\beta-\mathrm{CD} / \mathrm{OMC}+$ lipo/OMC formulation were $14.71 \pm 2.39 \mu \mathrm{g}$ and $15.26 \pm 3.47 \mu \mathrm{g}$, respectively - that is, they were similar in both epidermis and dermis.

\section{Discussion}

OMC (Figure 3C) is a chemical sunscreen derived from the cinnamate class, which absorbs UV-B and UV-A rays from the sun, protecting the skin from damage. In the molecular structure of cinnamates, there is an unsaturation conjugated with the aromatic ring and the carbonyl group, which allows better electronic distribution. The energy required to produce the electronic transition corresponds to a wavelength of $305 \mathrm{~nm} \cdot{ }^{27}$ It is an oily liquid, transparent, slightly yellow, odorless, and insoluble in water (water solubility $<0.1 \mathrm{~g} / 100 \mathrm{~mL}$ at $27^{\circ} \mathrm{C}$ ), although soluble in ethanol, propylene glycol, and mineral oil. Its molecular weight is 290.4 and boiling point is in the range of $185^{\circ} \mathrm{C}-195^{\circ} \mathrm{C}$. Its density is $1.01 \mathrm{~g} / \mathrm{cm}^{3} .{ }^{34}$ The octanol-water partition coefficient $\left(\mathrm{P}_{\mathrm{o} / \mathrm{w}}\right)$ for $\mathrm{OMC}$ is 5.96, indicating that it has high lipid solubility. Octanol may mimic the solvent properties of the stratum corneum; ${ }^{9}$ thus, OMC has an affinity for the lipid layer of the stratum corneum. 


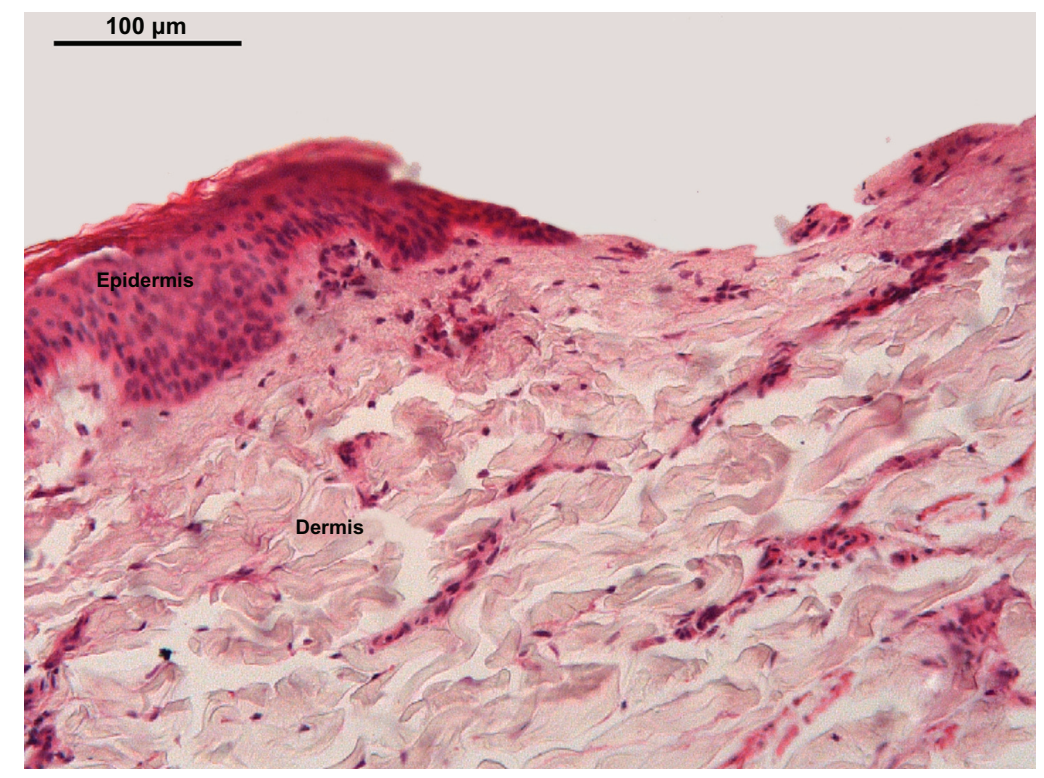

Figure 6 Light micrograph of the pig ear skin. The method totally removed the epidermis $(\mathrm{E})$, remaining the dermis. Notes: Staining with hematoxylin and eosin. Scale bar $=20 \mu \mathrm{m}$.

The American Association of Pharmaceutical Scientists recommends the use of phosphate buffer $\mathrm{pH} 7.4$ as a receptor medium in in vitro release studies by using diffusion cells for hydrophilic drugs, but the addition of surfactants in the buffer is allowed for lipophilic actives to maintain the sink conditions. ${ }^{31}$

Physical-chemical characterization shows that both empty liposomes and liposomes containing sunscreen have similar size distribution, PI, and zeta potential characteristics.

In this study, OMC sunscreen was included in two different release systems: liposomes and cyclodextrins. The lipo/OMC complex and $\beta-\mathrm{CD} / \mathrm{OMC}$ complexes were developed, characterized, and incorporated in gel cream. A third formulation was developed using the combination lipo/OMC complex and $\beta-\mathrm{CD} / \mathrm{OMC}$ complex. The ratio of the mixture was to obtain a synergistic effect. The formulation was $8 \%$ sunscreen, $4 \%$ of which was included in the cyclodextrin, and $4 \%$ in the liposomes. In vivo SPF, water resistance, and in vitro transdermal penetration tests were undertaken.

The in vitro SPF values of the sunscreen preparations were similar. These results may be due to the limitations of this method in assessing the interaction of the formulation, or the release system, with the skin. Thus, the method only determined the total content of OMC in the formulation. The major advantage of the in vitro test is its rapid and cost-effective screening methodology. In addition, in vitro tests can provide a formulation tool to identify new filters, optimize combinations of old ones, and pre-screen protective formulas prior to human in vivo tests.

Including OMC in liposomes increased the in vivo SPF values and water resistance, since the formulations with the

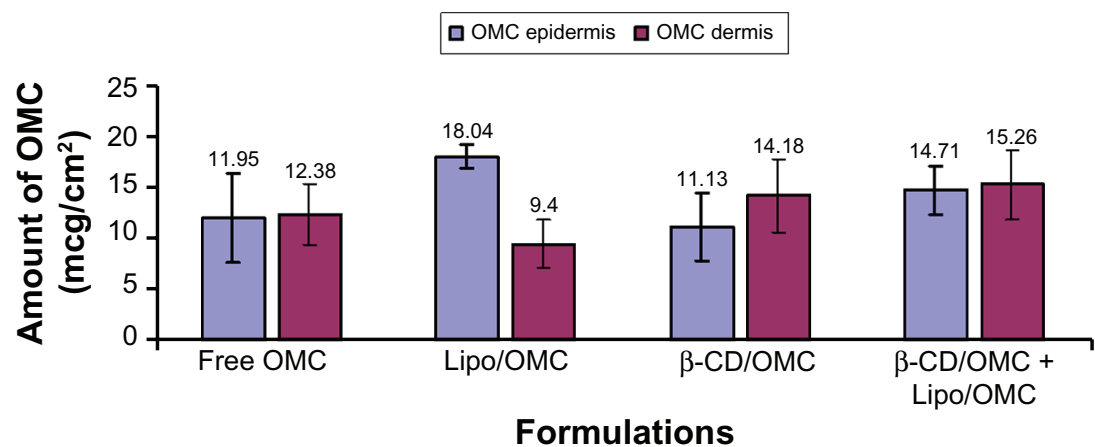

Figure 7 In vitro skin distribution of OMC in the epidermis and the dermis, 6 hours after application of cream with free OMC, cream with lipo/OMC complex, cream with $\beta-C D / O M C$ complex and cream with both complexes (mean \pm standard deviation, $n=4$ ).

Abbreviations: OMC, octyl p-methoxycinnamate; $\beta-C D, \beta$-cyclodextrins. 
lipo/OMC $+\beta-\mathrm{CD} / \mathrm{OMC}$ complex and the lipo/OMC complex exhibited the highest SPF values. The main phospholipid in the liposome preparation was soybean lecithin, which is similar to the phospholipids in biological membranes. This suggests a major interaction between the liposomes and the stratum corneum lipids that creates a reasonable environment for OMC to reservoir. Possibly due to these mechanisms, the sunscreen remains for longer on the skin's outermost layers, thereby increasing the SPF value. ${ }^{35}$ The inclusion of $\mathrm{OMC}$ in $\beta-\mathrm{CD}$ did not promote the increase of the in vivo SPF value, nor did it show any increase in water resistance. The in vivo test performed with formulations showed that the cyclodextrin complex had little effect on producing water resistance. The cyclodextrin formulation displayed a lower SPF value when compared with the cream control; additionally, it was found that cyclodextrin did not increase formulation adherence but enhanced the solubility of OMC in the water, when associated with OMC. ${ }^{18,20} \beta-\mathrm{CD} / \mathrm{OMC}$ is more hydrophilic than the sunscreen-free preparation, so it is less able to interact with the lipid layer of the skin. Further, as this complex was more hydrophilic, it was more easily removed from the skin surface by water, as seen in Figure 5. Also, the complex has the lowest SPF, due to low water resistance.

The use of pig ears in studies of skin care products has been widely discussed; the epidermis and dermis are important structures for these studies. ${ }^{36,37}$

Before permeation and retention studies, the skin samples were cleaned with SDS. The solution of 1\% SDS was used to remove excess fat from the skin surface, as excess fat could interfere with the permeation and retention studies. After cleaning, the skin was washed with distilled water to remove the SDS and gently dried with cotton to maintain the integrity of the skin.

The free OMC formulation demonstrated a similar amount of OMC in the pig epidermis and dermis after the in vitro cutaneous penetration test. The amount of OMC in the pig epidermis can be related to its high lipophilic nature. As a result, the affinity of OMC for the stratum corneum and remaining epidermis increased. This high affinity is particularly important for sunscreen, as the amount of sunscreen in the stratum corneum can be related to SPF. However, amounts of $\mathrm{OMC}$ in the dermis were found, demonstrating that $\mathrm{OMC}$ is able to penetrate the skin despite its high affinity for the stratum corneum.

In the $\beta-\mathrm{CD} / \mathrm{OMC}$ formulation, there was a higher amount of OMC found in the dermis. This can be attributed to cyclodextrin, which can be considered a permeation enhancer since both components interact with lipophilic compounds in the skin. Moreover, cyclodextrin can increase the topical transportation of some compounds by increasing their availability on the skin surface. The compound in the cyclodextrin cavity can be released by replacing other molecules with cavities with similar dimensions, such as skin lipids. If $\beta-\mathrm{CD} / \mathrm{OMC}$ is associated with the lipophilic region of biological membranes, like the cell membranes of the stratum corneum. These substances can be transferred to the extracellular space with more affinity. Buffer solutions containing $\beta-C D, R M-\beta C D$, and $H P-\beta C D$ are able to extract lipids from the stratum corneum. ${ }^{38}$ Irie and Uekama found that natural $\alpha, \beta$, and $\gamma$ cyclodextrins can cause skin irritation, which can be related to the ability of cyclodextrin to extract lipophilic compounds from the skin, like cholesterol and phospholipids, thereby increasing skin permeability and flow. ${ }^{39}$

The lipo/OMC formulation showed a higher amount of OMC in the epidermis, which is extremely significant for anti-solar formulations, and can be related to the liposome structure, which is similar to that of the cellular membrane. In this study, the liposomes' affinity for the stratum corneum resulted in a reservoir effect of OMC, since liposomes are able to interact with the lipid/water interfaces of the stratum corneum, spreading among the cells of the horny layer. Liposomes have been used as a vehicle for the controlled release of some substances, increasing their amount in the epidermis, and avoiding systemic absorption. ${ }^{40}$

The $\beta-\mathrm{CD} / \mathrm{OMC}+$ lipo/OMC formulation showed that the amounts of $\mathrm{OMC}$ in the epidermis and dermis were similar, which can be attributed to the presence of both complexes in the same formulation. The $\beta$-CD most likely acted as a permeation enhancer, releasing OMC from its cavity and allowing its incorporation with the phospholipids and cholesterol in the cell membranes of the stratum corneum. Thus, this skin layer was disorganized, allowing the diffusion of OMC for the dermis.

\section{Conclusion}

The formulation containing the lipo/OMC complex had the highest in vivo SPF and water resistance, as well as the best penetration test results. This suggests that the lipo/OMC systems promote a more effective anti-solar action than other formulations and demonstrates that the lipo/OMC system enhanced skin protection and remained on the skin for a reasonable period, conserving its effectiveness after exposure to water. Further, the lipo/OMC system demonstrated a significant increase of the amount of OMC 
in the epidermis, without increasing its penetration due to the development of OMC storage. The in vivo SPF and water resistance tests confirmed that the greatest retention of $\mathrm{OMC}$ in the epidermis enabled the increase of the in vivo SPF and the water resistance of the liposomal preparations, which consequently ensured a more efficient photoprotection.

\section{Acknowledgments}

MSSB Monteiro gratefully acknowledges the fellowship from Coordenação de Aperfeiçoamento de Pessoal de Nível Superior (CAPES), Farmácia Universitária/UFRJ, and the technical support provided by LabCQ/UFRJ.

\section{Disclosure}

The authors report no conflicts of interest in this work.

\section{References}

1. National Institutes of Health. National Institute of Health Consensus Development Conference Statement [web page on the Internet]. Available from: http://cool.conservation-us.org/bytopic/health/uvnih. html. Accessed October 1, 2010.

2. Kullavanijaya P, Lim HW. Photoprotection. J Am Acad Dermatol. 2005; 52(6):937-958.

3. Merwald H, Klosner G, Kokesch C, Der-Petrossian M, Honigsmann H, Trautinger F. UVA-induced oxidative damage and cytotoxicity depend on the mode of exposure. J Photochem Photobiol B. 2005;79(3):197-207.

4. Sarveiya V, Stacey R, Benson HA. Liquid chromatographic assay for common sunscreen agents: application to in vivo assessment of skin penetration and systemic absorption in human volunteers. J Chromatography B. 2004;803(2):225-231.

5. Simeoni S, Scalia S, Benson HA. Influence of cyclodextrins on in vitro human skin absorption of the sunscreen, butyl-methoxydibenzoylmethane. Int J Pharm. 2004;280(1-2):163-171.

6. Nohynek GJ, Schaefer H. Benefit and risk of organic ultraviolet filters. Regul Toxicol Pharm. 2001;33(3):285-299.

7. Scalia S, Tursilli R, Ianuccelli V. Complexation of the sunscreen agent, 4-methylbenzylidene camphor with cyclodextrins: effect on the photostability and human stratum corneum penetration. $J$ Pharm Biomed Anal. 2007;44(1):29-34.

8. Godwin DA, Kim NH, Felton LA. Influence of Transcutol CG on the skin accumulation and transdermal permeation of ultraviolet absorbers. Eur J Pharm Biopharm. 2002;53(1):23-27.

9. Jiménez MM, Pelletier J, Bobin MF, Martini MC. Influence of encapsulation on the in vitro percutaneous absorption of octyl methoxycinnamate. Int J Pharm. 2004;272(1-2):45-55.

10. Alvarez-Román R, Barré G, Guy RH, Fessi H. Biodegradable polymer nanocapsules containing a sunscreen agent: preparation and photoprotection. Eur J Pharm Biopharm. 2001;52(2):191-195.

11. Anselmi C, Centini M, Rossi C, et al. New microencapsulated sunscreens: technology and comparative evaluation. Int $J$ Pharm. 2002;242(1-2):207-211.

12. Scalia S, Casolari A, Iaconinoto A, Simeoni S. Comparative studies of the influence of cyclodextrines on the stability of the sunscreen agent, 2-ethylhexyl-p-methoxycinnamate. J Pharm Biomed Anal. 2002;30(4): 1181-1189.

13. Morabito K, Shapley NC, Steeley KG, Tripathi A. Review of sunscreen and the emergence of non-conventional absorbers and their applications in ultraviolet protection. Int J Cosmt Sci. 2011;33(5): 385-390.
14. Morganti P. Use and potential of nanotechnology in cosmetic dermatology. Clin Cosmet Investig Dermatol. 2010;3:5-13.

15. Betz G, Aeppli A, Menshutina N, Leuenberger H. In vivo comparison of various liposome formulations for cosmetic application. Int J Pharm. 2005;296(1-2):44-54

16. Mukherjee B, Padra B, Layek B, Mukherjee A. Sustained release of acyclovir from nanoliposome and nanoniosomes: an in vitro study. Int J Nanomed. 2007;2(2):213-225.

17. Elsayed MM, Abdallah OY, Naggar VF, Khalafallah NM. Lipids vesicles for skin delivery of drugs: reviewing three decades of research. Int $J$ Pharm. 2007;332(1-2):1-16.

18. Mota AC, Volpato NM, Freitas ZM, Santos EP. Estudo de liberação in vitro do filtro solar p-metoxicinamato de octila incluso em lipossoma e beta ciclodextrina [In vitro release study of the sunscreen octyl p-methoxycinnamate and included in beta cyclodextrin liposome]. Rev Ciênc Farma Básica Apli. 2008;29:285-289. Portuguese.

19. Marques HMC. Preparations of complexes: evidence for complex formation. Rev Port Farm. 1994;4:157-163.

20. Coelho GL, Dornelas CB, Soares KC, et al. Preparation and evaluation of inclusion complexes of commercial sunscreens in cyclodextrins and montmorillonites: performance and substantivity studies. Drug Dev Ind Pharm. 2008;34(5):536-546.

21. Mansur JS, Breder MNR, Mansur MCA. Determinação do fator de proteção solar por espectrometria [Determination of sun protection factor spectrometry]. Ann Bras Derm. 1986;61:121-124. Portuguese.

22. Santos EP, Freitas ZM, Souza KR, Garcia S, Vergnanini A. In vitro and in vivo determinations of sun protection factors of sunscreen lotions with octylmethoxycinnamate. Int J Cosm Sci. 1999;21(1):1-5.

23. Freitas ZM, Gonçalves JC, Santos EP, Vergnanini A. Glyceridic esters of $p$-methoxycinnamic acid. A new sunscreen of the cinnamate class. Int J Cosm. 2001;23(3):147-152.

24. Sayre RM, Agin PP, LeVee GJ, Marlowe E. Comparison of in vivo and in vitro testing of sunscreening formulas. Photochem Photobiol. 1979;29(3):559-566.

25. COLIPA. The European Cosmetic, Toiletry and Perfumery Association - International Sun Protection Factor (SPF) Test Method. 2006. Available from: www.colipa.eu/downloads/ 86 .html. Accessed October 1, 2010

26. Ruvolo-Júnior EC. Proteção solar: comparação dos métodos de determinação por testes em humanos (in vivo), FDA, COLIPA, SAA [Sunscreen: comparison of measurement methods for testing in humans (in vivo), FDA, COLIPA, SAA]. Cosmetics Online. 1997;19(105): 37-46. Portuguese.

27. Shaath NA. Evolution of modern sunscreen chemicals. In: Lowe NJ, Shaath NA, Pathak MA, editors. Sunscreens Development, Evaluation, and Regulatory Aspects. New York: Marcel Dekker; 1997: 589-600.

28. Organization for Economic Co-operation and Development (OECD). OECD Guideline for the Testing of Chemicals: Skin Absorption: In Vitro Method. Test number 428. Paris: OECD; 2004. Available from: http://iccvam.niehs.nih.gov/SuppDocs/FedDocs/OECD/OECDtg428. pdf. Accessed March 5, 2012.

29. Barth AB, Pereira RL, de Vargas BA, Volpato NM. A simple and rapid method to assess butenafine hydrochloride in skin samples and a comparative cutaneous retention study of two marketed formulations. Biomed Chromatogr. 2011;25(19):1132-1137.

30. Lillie RD, Fullmer HM. Histopathological Technique and Practical Histochemistry. 4th ed. New York: McGraw-Hill; 1976.

31. Siewert M, Dressman J, Brown CK, Shah VP. FIP, AAPS. CIP/AAPS guidelines to dissolution/in vitro release testing of novel/special dosage forms. AAPS Pharm Sci Tech. 2003;4(1):E7.

32. Dodziuk H. Rigidity versus flexibility. A review of experimental and theoretical studies pertaining to the cyclodextrin nonrigidity. $J \mathrm{Mol}$ Struct. 2002;614:33-45.

33. Zatz JL. Drug release from semisolids: effect of membrane permeability on sensitivity to product parameters. Pharm Research. 1995;12(5):787-789. 
34. O'Neil MJ, Smith A, Heckelman PE, Obenchain JR, Gallipeau JR, D'Arecca MA, editors. The Merck Index: An Encyclopedia of Chemicals, Drugs, and Biologicals. 13th ed. Whitehouse Station, NJ: Merck Co Inc; 2001.

35. Bhatia KS, Gao S, Singh J. Effect of penetration enhancers and iontophoresis on FT-IR spectroscopy and LHRH permeability through porcine skin. J Control Rel. 1997;47:81-89.

36. Bhatti AS, Scott RC, Dyer A. In vitro percutaneous absorption: pig epidermal membranes as a model for human skin. JPharm Pharmacol. 1989;41:40-45.

37. Meyer W, Zschemisch NH. Die Hautschichten am Ohr des Hausschweins, mit besonderer Berücksichtigung der Nutzung des Ohrinteguments in der humandermatologischen Forschung [Skin layer thickness at the ear of the domesticated pig, with special reference to the use of the ear integument for human dermatological research]. Berl Münch Tierärztl Wochenschr. 2002;115(11-12):401-406. German.
38. Serpone N, Dondi D, Albini A. Inorganic and organic UV filters: their role and efficacy in sunscreen and suncare products. Inorg Chim Acta. 2006;360(3):794-802.

39. Irie T, Uekama K. Pharmaceutical applications of cyclodextrins. III Toxicological issues and safety evaluation. J Pharm Sci. 1997;86(2): 147-162.

40. Terra RS, Minin MM, Chorilli M. Development and evaluation of physicalchemistry formulation stability increased with liposome containing synephrine and caffeine. Rev Bras Farm. 2009;90(4):303-308.

\section{Publish your work in this journal}

The International Journal of Nanomedicine is an international, peerreviewed journal focusing on the application of nanotechnology in diagnostics, therapeutics, and drug delivery systems throughout the biomedical field. This journal is indexed on PubMed Central, MedLine, CAS, SciSearch ${ }^{\circledR}$, Current Contents ${ }^{\circledR} /$ Clinical Medicine,
Journal Citation Reports/Science Edition, EMBase, Scopus and the Elsevier Bibliographic databases. The manuscript management system is completely online and includes a very quick and fair peer-review system, which is all easy to use. Visit http://www.dovepress.com/ testimonials.php to read real quotes from published authors. 